\title{
Environmental Kuznets Curve for Sustainable Development
}

\author{
Oum Kumari R, Sunita Choudhary, Mohammed Sani Ibrahim
}

\begin{abstract}
Economies today are relying on coal and other finite sources for their energy needs which has not only resulted in exhaustion of finite resources but also has adversely affected the environment as burning of coal alone is responsible for emission of Green House Gases. As the economy grows the consumption of power also rises and in order to keep pace with the growing demand for power, economies are forced to increase the installed capacity. But in economies like US, China and India dependence on coal has been in rise for last few decades. Simon Kuznet rightly brought this to our notice and established the relationship between carbon emission and GDP which would be positively related initially but growth in GDP would enable the economies to find out some alternatives and reduce the emissions $n$ long run. This paper critically analyses the existence of hypothesized relationship of Environmental Kuznets Curve (EKC) between Gross Domestic Product (GDP) and CO2 emissions of U.S., India and China. In trying to prove the theoretical framework that economic growth (GDP) in terms of purchasing power parity and environmental deterioration are strongly related, the paper used the data of developed and developing countries mentioned above. The main aim of the paper is to check the applicability of Environmental Kuznets Curve (EKC) on the economic growth of U.S., China and India. The researcher used regression for time series analysis in analyzing the data from 1999-2018. The paper is divided into three sections with the first section covering the introduction; the second section is theoretical framework. Data analysis and presentation of findings formed the third section. The researcher finally concluded the paper by giving some suggestions in lieu of the findings.

Keywords : Environmental Kuznets Curve, Co2 emission, GDP, Environmental Degradation.
\end{abstract}

\section{INTRODUCTION}

$\mathrm{I}_{\mathrm{n}}$ $\mathrm{n}$ the quest for rapid economic and developmental goals achievements, demand for and utilization of energy are inevitable. Countries of the world have been increasing the level of their energy consumption due to expansion in economic activities and thus emit $\mathrm{CO} 2$ to the atmosphere as a result of use of conventional sources of energy such as coal, oil and gas. This implies that increase in economic growth lies with increase in energy production and consumption (electricity, oil and gas, etc.). U.S., China and India are the world leaders of energy consumption. These leaders of energy consumption, therefore, contribute immensely to the increase in the level of $\mathrm{CO} 2$ emissions, which contaminate the

Revised Manuscript Received on October 31, 2019.

* Correspondence Author

Oum Kumari*, Department of Economics , Manipal University Jaipur, India.Email: oum.rathore@gmail.com

Mohammed Sani Ibrahim, *, Department of Economics , Manipal University Jaipur, India. Email: mosaib2009@ gmail.com

Sunita Choudhary*, Department of Economics , Manipal University Jaipur, India. Email: sunitachoudhary.jpr@gmail.com environment and result in climate change. Emissions in these countries are considered to be a function of electricity consumption, electricity production from non-renewable energy sources and Gross Domestic Product (PPP) as used in this paper. China and India whose main energy source is coal have witnessed high economic growth and utilization of coal in recent decades while about $30 \%$ of U.S.'s electric power supply is from coal down from 39\% in 2017 and 50\% in 2007 and it is expected to dip to $24 \%$ in 2020 [8]. Coal as the main source of electricity in these countries is responsible for $32 \%$ of the greenhouse gas emission in United States [3]. India and China, both, showed notable increase in total world energy consumption percentage which was ten percent in 1990 to twenty-one percent in 2008 and are anticipated to increase their demand for energy to about $30 \%$ in 2035 . Coal formed about three quarters of electricity source in both India

and China. The robust growth in the economy of India and China is expected to be accompanied by increase in the present level of coal consumption which will

consequently have an influence on carbon dioxide emissions while coal consumption in United States decreased in recent years due to increase in power generation through renewable resources to the tune of $17.6 \%$ in 2018 [8]. Solar energy share in total power generation has increased from 2 million Mwh in 2008 to 96 million Mwh in 2018 and this makes $2.3 \%$ of electricity generation in 2018. China, which emits carbon from burning fossil fuels more than the Europe and United States put together [4], noticed an increase in electricity use in 2017 as its economy speeded up. In US, carbon dioxide emissions from power sector have reduced by $28 \%$ since 2005. Much of the demand gap was met by burning additional coal while demand for gas has gone up [4]. Oil and natural gas consumption in China have also gone up as it is the largest car market in the world. More than a quarter of global warming gasses are produced by China. According to EESI, the U.S. produces around $17.6 \%$ of the world's natural gas and consumes about $21.6 \%$ of it (as of 2015). A detailed data recently released by China's National Development and Reform Commission showing an increase of 6.6 percent in the electricity consumption of the country in 2017. There was also a speedy increase in wind and solar energy, but not to the extent of meeting the extra electricity demand [4]. In China, there was increase in electricity generation from burning of fossil fuels in 2017 to the tune of 5.2 percent which was dominated by coal. Several warnings came from scientists that the drop in CO2 emissions of China in 2015 and 2016 might be raised, and the recently released data proved that. 
Also, India is known to emit large amounts of $\mathrm{CO} 2$ due to increase in burning of coal for electricity generation to meet its increasing demand for power. Although, reduction in the level of energy consumption appears to be a good choice in cutting down $\mathrm{CO} 2$ emissions but can have a negative impact economic development. For instance, coal consumption in China as percentage of total energy consumption is about $69 \%$ and that of India is $65 \%$ and any effort to reduce it may have potential negative influence on the economic growth. India is using Bituminous and subbituminous type of coal. This type of coal has (i) low calorific value (ii) higher ash content that increases the co 2 emission in the country. There is therefore the need to understand the dynamic relationship between coal consumption, $\mathrm{CO} 2$ emissions and economic development in U.S, India and China. Coal plays a significant role in economic growth and development and is the source with largest share of world $\mathrm{CO} 2$ emissions representing one-third of the share of fossil fuels in the global total primary energy supply but causing about $43 \%$ of the Carbon dioxide emissions. India produces and imports coal from different countries to meet its energy demand and that increases carbon emission in the country. In 2013, approximately 36 Gt CO2 was emitted to the atmosphere globally with U.S., China and India as leading emitters.

To keep the trend of economic growth, electricity must be produced and consumed. To reduce or control the emissions, investments in renewable sources of energy such as solar energy must be made. Earlier researchers have found a positive relationship between the $\mathrm{Co} 2$ emissions and growth in income but after reaching its highest point the relationship among the variables becomes negative. Electricity production and consumption show a positive relationship with $\mathrm{CO} 2$ as the energy is produced through coal. And demand for electricity increases with increase in population which increases the $\mathrm{CO} 2$ because the electricity source is non-renewable [13]. In this case, to reduce $\mathrm{CO} 2$, electricity consumption and production cannot be decreased as growth cannot be stopped but change can be made in the source of electricity production that doesn't add to $\mathrm{CO} 2$ emissions and this is by adopting renewable energy resources.

Many researches have been carried out on Environmental Kuznets Curve (EKC) Hypothesis but none of them have attempted to comparatively prove the existence of EKC on U.S., China and India being leaders of electricity consumption and $\mathrm{CO} 2$ emissions in the world with emphasis on these variables; electricity production, electricity consumption, GDP at purchasing power parity and emissions from non-renewable energy sources. The focus of this paper is therefore on how emissions can be controlled without compromising the increasing trend of economic growth of U.S., China and India while increasing the level of electricity production and consumption.

The Uniqueness of this paper is that it appears to be the first to consider U.S., China and India together for comparative applicability of Environmental Kuznets Curve (EKC). These three countries are the top $\mathrm{CO} 2$ emitters in the world with China topping the list by emitting 9,297 $\mathrm{MtCo} 2$, followed by U.S. which emits 5,073 Mtco2 and India occupying the third position by releasing 2,234 Mtco2. These countries are also the largest producers and highest consumers of electricity in the world in the same sequence.

The researcher has used the scatter diagram to show the applicability of EKC on U.S., China and India and linear regression is used as statistical tool to analyze the data to show the relationship among the variables.possible.

\section{THEORETICAL FRAMEWORK}

\section{A. Environmental Kuznets curve (EKC)}

Environmental Kuznets Curve (EKC) Hypothesis is a concept developed by Simon Kuznets, an American economist in the 19th century. Grossman and Krueger in their 1991 study of the potential impacts of North American Free Trade Agreement (NAFTA) made this notion known [1]. Also, the World Bank Development Report (IBRD, 1992) greatly helped in popularizing this concept which stated that greater activity of the economy inevitably degrades the environment was based upon some assumptions about environmental investments, tastes and technology and therefore increase in income will be accompanied by increase in the demand for improvement in quality of the environment [1][6]. Another argument came from Beckerman in 1992 who argued in support of EKC concept that there was clear proof that, although the growth in the economy usually translates to environmental degradation in the early stages of the process, but in the long run the best and probably the only way to attain a qualitative environment in nearly all countries is by becoming rich [1]. Lomborg, in his popular book 'Skeptical Environmentalist' also joined this argument in 2001 and relied on the 1992 World Bank Development Report (IBRD, 1992) and his argument was in support of EKC hypothesis [1] . Despite the argument offered by the above environmentalists and economists for EKC hypothesis, some environmental economists were highly against the notion of EKC. The intensity of Carbon dioxide emissions gives an important test of the Environmental Kuznets curve EKC hypothesis for about four reasons, which include; First, carbon dioxide observed to contribute for more half of the effect of greenhouse warming. Second, until recently, Carbon dioxide was considered a harmless by- product of efficient and clean combustions. Third, there is obviously no thermodynamically necessary to limit the amount of Carbon dioxide which a country must emit to have a certain size of economy or population. Fourth, $\mathrm{CO} 2$ emissions estimates are available for more countries and years than are the measures of other pollution types [1]

Most empirical studies on EKC used international data and limited data largely on air and water pollutants. Pollutant emissions (flow) and concentrations (Stocks) were used to measure environmental quality. In general, it was found that the EKC relationship is more likely for some pollutants, including SO2, Particulate matter, nitrogen oxide (NOx), etc., but less likely for carbon dioxide. Results are more mixed for water polluters than for air pollutants. Proof of EKC for some Water quality indicators are weak or contradictory (eg, Hettige et al., 2000, Shafik, 1994). As Points, although large differences are found between the studies even for the same pollutant, most fall into the per - capita income range of $\$$ 5,000 to $\$ 8,000$. Halkos (2003) found this on the basis of a globally representative panel data set . 
The turning point of SO2 is estimated at $\$ 5,648$ per KKP per capita for the organization Sub-sample for Economic Co-operation and Development (OECD) and 3.401 USD for Subsample of the OECD.

For the shape of Environmental Kuznets Curve, a lot of literatures have been put forward by many researchers regarding the shape of Environmental Kuznets Curve. The original EKC was inverted "U" but after many empirical studies many shapes were put forward among which is " $\mathrm{N}$ " shaped EKC. Allard et al. (2017) have discussed the "N" shaped EKC showing the relationship between the GDP per capita and $\mathrm{CO} 2$ emission and used panel quantile analysis as a methodology and the other variables used in the study are renewable energy consumption, technological development, trade and institutional quality. The research is conducted in three different income groups of countries covering 74 countries over the period of 1994-2012. The study found that the " $\mathrm{N}$ " shaped EKC is in lower middle income countries and $\mathrm{CO} 2$ emission can be reduced by encouraging the green technology. In India, there are many empirical studies done on EKC as in paper [13] studied the relationship among energy consumption, economic growth and carbon emission at the aggregated and disaggregate level from the period of. This study proves the relationship among these variables in all the sectors like agriculture, domestic, industrial and commercial, and also at the aggregated level in the long run [13]. One more study took place on India for testing the policy of Kyoto protocol and assessing the probability of EKC on India. In paper [14] they used data from 1971to 2013 and applied the ARDL model of co-integration. The study shows that there is a long term relationship between the co2 emission, GDP growth, energy consumption and trade openness and therefore the EKC hypothesis in case of India shows the need to take strict actions to control $\mathrm{CO} 2$ emission [14] while a study on china in 2011 divided china into three regions as central, eastern and western region to test the EKC hypothesis and took GDP per capita and carbon emission per capita of China as variables. As a result both eastern region and central region show the inverted "U" shaped EKC but western region shows "U" shaped EKC. In the long run inverted "U" shape doesn't change but in short run industrial structure, energy consumption structure, technological level and structure of export trade can affect the shape of the curve. It also suggests that if carbon intensity reduction rated is $3 \%, 5 \%$ and $10 \%$ the inflexion point can be accomplished by 2023, 2021 and 2017[15].

\section{B. CO2 Emission and economic growth of U.S., China, and India}

The rising global emissions every year put many lives and economies of billions of people in danger. The terrible impacts of climate change of $10 \mathrm{C}$ as warning has become evident. According to EIA's estimates, there was $2.8 \%$ increase of energy related carbon dioxide (CO2) emissions in 2018 but will face reduction in 2019 and 2020 [2]. Triggered disasters in 2017 caused by weather and climate cost the global economy US320 billion in addition to about 10,000 lives lost. 21 countries have grown their economies while shrinking their emissions since 2000 [2]. U.S, China and India, due to the expansive nature of their economies, heavily rely on fossil fuels for electricity generation especially coal. The amount of fossil fuels used for generation of electricity and industrial processes has greatly increased. Moreover, with increase in generation capacity of coal-fired plants in India and China, there is expectation of increase in consumption of coal. Coal consumption by industries from 2008 to 2035 is expected to rise by $94 \%$ in India and $67 \%$ in China [3]. Coal consumption increased by $71 \%$ between 2003 and 2008. China, in 2008 was the top CO2 emitter in the world overtaking the United States while India ranked at third position. The per capita $\mathrm{CO} 2$ emissions in China increased by two and a half times, while that of India increased two times [3]. Forecast shows that from 2005 to 2030 annual CO2 emissions will rise 2.5 times and will reach 3084 million tons (Mt) in 2030 and therefore put annual growth to the tune of $3.7 \%$ in India [3]. China, in 1996, accounted for $13.8 \%$ of the global $\mathrm{CO} 2$ emissions and in 2007 the share increased to $21 \%$. The biggest challenge for the leaders of countries of India and China is on how to manage their economic growth and at the same time keeping at acceptable level of $\mathrm{CO} 2$ emissions as well as coal consumption in such a way that the economic growth of the countries is not harmed [4]. The United States is the largest country to have fallen $\mathrm{CO} 2$ emissions of $6 \%$ since 2010. CO2 emissions, coal consumption and real GDP of India and China over the periods of 1965 to 2009 indicated an increasing trend [4]. According Rhodium estimates, China's energy-related carbon emissions in 2017 raised to $4.1 \%$ from 2.2 percent. By comparison, China somewhat had low industrial production in the second half of 2015 and the early part of 2016 because of financially related problems [4]. That wounded the Chinese economy and the consumption of fossil fuels in both years. China still sources its three-quarters of its electricity by burning coal [4]. CO2 emissions of India increased from 615 Mt in 1990 to 1897 Mt in 2013, showing an overall CAGR of about $5 \%$. CO2 emissions in India accounted for $2.7 \%$ of world CO2 emissions in 1990 and grew to around 5\% in 2013 [7]. Although, India was placed behind China, the U.S. and the Europe in national CO2 emissions in 2013, its growth trend is appreciably greater and second only to China globally. The contribution of coal to India's $\mathrm{CO} 2$ emissions in 2013 was $62 \%$ and in 2018 accounted for $65 \%$, while oil products accounted $27 \%$ and that of natural gas was $4 \%$ [7] [6]. From 2014 the world experienced a relatively stable carbon dioxide emission for three consecutive years. In 2017, $\mathrm{CO} 2$ emissions of India increase by an estimated $4.6 \%$ to about 2.4 billion tons despite a turbulent year for its economy [7].The intensity of energy in the economy of India went down by $32 \%$ from 1990 to 2005 and by $11 \%$ for the period 2005 to 2013. The corresponding decrease in the CO2 emission intensity of GDP was calculated to be $17 \%$ and $11 \%$ respectively, showing rising $\mathrm{CO} 2$ intensity of energy sector of India, mainly due to enhanced use of coal [7].

In addition, the rising emissions from the use of coal may adversely affect India's achievement of Paris commitment target, especially under a scenario of low economic growth [7]. In recent decades, both India and China have made significant progress with reforestation and age still able to do more; further tree planting could lead to removal of $1.25 \mathrm{Gt}$ and $520 \mathrm{Gt}$ of $\mathrm{CO} 2$ per year in each of the two countries [8] 


\section{REVIEW ANALYSIS OF DATA AND PRESENTATION OF FINDINGS}

This paper evaluates the environmental Kuznets curve holding in USA, china and India. The data used in this study were sourced from World Bank's World Development Indicators from 1999-2018. For countries' economic growth we used GDP ppp (current international \$) and for environmental degradation co2 emission, Electricity consumption, and Electricity generation from oil, gas and coal. In this part of the paper, we will check the applicability of EKC hypothesis on U.S., China and India.

The variables used in the study are Carbon Emission (DV), Energy Consumption ( IV), Energy Production from coal (IV), Energy Producton from Oil and Gas(IV) and GDP ppp (IV)

The results of the regression in table 1 and table 2 clearly brought out the fact that the Carbon emission (CO2) of all the three countries i.e USA, China and India is strongly influenced by all the four Exogenous variables taken for the study i.e. Energy consumption, electricity production from coal oil and gas and GDP (PPP). R value in the given table also shows strong positive correlation between Dependent Variable (DV) and Independent Variable (IV) the given variable. $R$ Square value and $F$ value in table 12 clearly bring out the fact that all the variables are responsible for increasing $\mathrm{CO} 2$ emission.

India is a lower middle income country, it shows the "N" shape EKC (Dinda, 2004). Since 1999 GDP ppp is increasing with increase in $\mathrm{co} 2$ emission. And in the year 2004 co2 emission reaches its maximum point at $56.88 \%$ and GDP ppp is 2.87 billion $\$$, after this point co 2 emission starts falling and reaches it minimum point at $51.50 \%$ showing neagative growth rate. But after minimum point it starts rising again which shows that in the short run India's EKC follows EKC hypothesis but in the long run it doesn't follow.

China is an upper middle-income country. Since 1999, co2 emission in china is increasing with increase in GDP ppp. In 2003 co 2 emission reaches its highest point $52.62 \%$ and GDP is 5.1 billion $\$$. After $2003 \mathrm{Co} 2$ emission falls, and fluctuate by one or two percentage and GDP ppp keeps on increasing this shows that in case of china EKC is at its upper limit.

United States of America is a high-income country having GDP (PPP) 19 trillion \$ in 2017. In figure 3, it shows the relationship between the environmental degradation and economic growth of USA. As in the year $2000 \mathrm{co} 2$ emission is highest at $49.31 \%$ and GDP is 8 trillion \$. After this point co2 emission starts falling with increase in GDP (PPP), it shows negative growth rate after 2012 , which proves that it follows the EKC

\section{CONCLUSION/SUGGESTIONS}

Attempt has been made in this paper to prove the existence of EKC Hypothesis on U.S, China and India. According to Simon Kuznets the income distribution will grow more unevenly at the beginning of economic growth but will ultimately starts to equalize as growth continues. In relation to these results, it is stated that economic growth and improvement in environmental conditions are not necessarily contradictory, if necessary steps are taken. From the results presented in figure 1, $2 \& 3$, EKC proved to hold true for U.S. and in some way China. For India, the above said words were true as $\mathrm{CO} 2$ emission starts falling with increase in economic growth, but after 2010, it started rising again forming an $\mathrm{N}$-shaped. This is due to weak policy in India. In other words, environmental protection policies have been more effective in U.S. and China as compared to India. The following suggestions can definitely go a long way in achieving EKC in developing economies.

\section{A. Investment in clean energy}

It has been observed that U.S. is able to achieve the EKC due to its huge investment in clean energy. In 2004 U.S.'s investment was $\$ 10.4 \mathrm{bn}$ and it was increased to $\$ 56.9 \mathrm{bn}$ in 2017. The growth rate in increase in investment is $547.11 \%$ in clean energy. China's investment in 2004 was $\$ 3.1$ bn and increased to \$132.6bn in 2017 in clean energy, therefore the growth rate was $4177.4 \%$ this is higher growth rate than U.S.

But in the case of India the amount of investment in clean energy in 2004 was $\$ 2.7$ bn and it rose to $\$ 11$ bn in 2017 , growth rate was $307.40 \%$ which is lowest in terms of money expenditure and in percentage of growth among these countries. India needs to increase its investment in clean energy.

\section{B. Research and development}

Research and development is the main area for any country to walk the path from developing to developed country. From the above discussion, we have seen that developed countries are investing more in clean energy. According to the 2018 Global R\&D Funding forecast, U.S. share of research and development is huge. As in 2016, the GDP (PPP) of U.S. is $\$ 18569.10$ bn and it was forecasted that it would increase to $\$ 194712.84$ bn. The share of Research and Development (R\&D) in 2016 in $2.81 \%$ of GDP (PPP) and it will be increased to $2.81 \%$ in 2018 . China's GDP (PPP) is $\$ 21.290 \mathrm{bn}$ in 2016 and it would increase to \$24102bn in 2018 and the share of $R \& D$ was $1.94 \%$ in 2016 and it was predicted to increase to $1.97 \%$ of GDP (PPP) However, in the case of India where GDP ppp is \$8.662bn in 2016 and increased GDP (PPP) would be \$9796bn in 2018 and the share of R\&D in 2016 was $0.85 \%$ of GDP and it would increase to $0.85 \%$, which is lowest among these three countries. So in order to achieve the EKC India need to increase the money expenditure in research and development. 
A. Table 1 Model summary

\begin{tabular}{|c|c|c|c|c|c|c|c|c|}
\hline \multirow[t]{2}{*}{ Model } & \multirow[t]{2}{*}{$\mathrm{R}$} & \multirow[t]{2}{*}{$\begin{array}{c}\mathrm{R} \\
\text { Square }\end{array}$} & \multirow{2}{*}{$\begin{array}{r}\text { Adjuste } \\
\mathrm{d} \text { R } \\
\text { Square }\end{array}$} & \multirow{2}{*}{$\begin{array}{c}\text { Std. } \\
\text { Error } \\
\text { of the } \\
\text { Estimate }\end{array}$} & \multicolumn{4}{|c|}{$\begin{array}{l}\text { Change } \\
\text { Statistics }\end{array}$} \\
\hline & & & & & R Square Change & $\begin{array}{c}\mathrm{F} \\
\text { Change }\end{array}$ & df1 & $\begin{array}{l}\text { Sig. F } \\
\text { Change }\end{array}$ \\
\hline India & $.748^{\mathrm{a}}$ & .559 & .442 & 1.31571 & .559 & 4.758 & 4 & .011 \\
\hline China & $.875^{\mathrm{a}}$ & .765 & .703 & 1.67074 & .765 & 12.220 & 4 & .000 \\
\hline USA & $.819^{\mathrm{a}}$ & .671 & .583 & .56343 & .671 & 7.631 & 4 & .001 \\
\hline
\end{tabular}

Table 2 Anova

\begin{tabular}{|l|l|l|l|l|l|l|}
\hline Country & Model & $\begin{array}{l}\text { Sum } \\
\text { of } \\
\text { squa } \\
\text { res }\end{array}$ & Df & Mean Square & F & Sig. \\
\hline India & Regression & 32.949 & 4 & 8.237 & 4.758 & .011 \\
& Residual & 25.966 & 15 & 1.731 & & \\
& Total & 58.915 & 19 & & 12.220 & .000 \\
\hline China & Regression & 136.440 & 4 & 34.110 & & \\
& Residual & 41.871 & 15 & 2.791 & 7.631 & .001 \\
& Total & 178.311 & 19 & & & \\
\hline USA & Regression & 9.691 & 4 & 2.423 & & \\
& Residual & 4.762 & 15 & .317 & & \\
& Total & 14.452 & 19 & & & \\
\hline
\end{tabular}

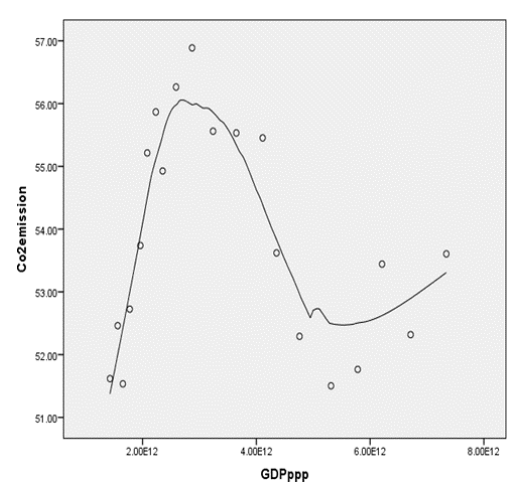

Fig.1 India's Environmental Kuznets Curve

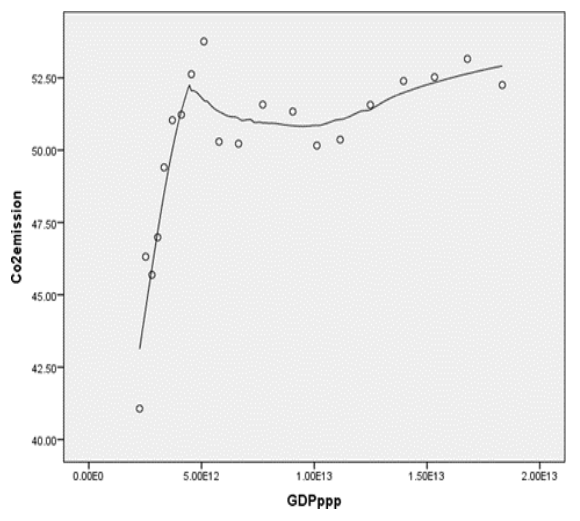

Fig.2 China's Environmental Kuznets Curve

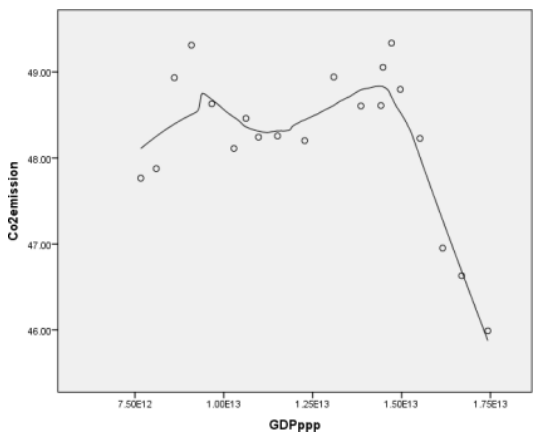




\section{C.Skill development}

Suryamitra is a recently introduced programme by government of India. It is a skill development programme organized by National institute of Solar Energy. In this programme youth are trained in manufacturing, installation and maintenance of solar equipment, the thought was given to meet up the growing demand of skilled labors in solar industry. It is organized for 90days (3 months) in 119 centers of the country. Programme like this should be increased to each district of the country which makes people more acquainted to renewable energy.

\section{D.Awareness programs}

Awareness programmes for renewable energy should be organized in both government and private organizations in a large scale. Students should be taught practical knowledge of renewable energy in both schools and colleges. This spreads the awareness among the people regarding renewable energy. Acceptance of solar energy will help reduce the carbon emissions in the environment thereby keeping environment safe, creating job opportunities, improving living standard and the health of people and will ultimately help in improving the quality of life.

\section{REFERENCES}

1. Shahbaz, M., Sinha, A.: “ Environmental Kuznets Curve foe co2 emissions: a Literature Survey". Journal of Economic Studies vol. 46.1. Emerald group Publishing LTD., UK (2019)106-168

2. Dinda, S., Environmental Kuznets Curve Hypothesis: A Survey. Ecological Economics vol.49. Elsevier BV.,Netherlands (2004)431-455

3. International Energy Agency Outlook (2011) annual report

4. The New York Times (Jan. 25th ,2017) ; China's emission s more than U.S plus Europe, and still rising

5. Manuel, A. Zambrano-Monserrate, Christopher Carvajal-Lara \& RobertoUrgiles-Sanchez.: Is there an inverted U-shaped Curve? Empirical analysis of the Environmental Kuznets Curve in Singapore. Asia Pacific Journal of Accounting and Economics. Vol 25,1-2, Taylor and Francis., UK (2018)145-162

6. Ahmed,K.,Long,W.: An empirical analysis of co2 emission in Pakistan using EKC hypothesis. Journal of International Trade Law and Policy, vol. 12. 2. Emerald group Publishing LTD., UK (2013)188-200

7. V.G.R. Chandran Govindaraju and Chor Foon Tang (2013) ; The dynamic links between $\mathrm{CO} 2$ emissions, economic growth and coal consumption in China and India

8. U.S. Energy Information Administration. U.S. energy -related co2 emission fall 1.7\% in 2016 ( eia, Independent Statistics and Analysis) Washington ,DC U.S. (2017): Perry Lindstrom

9. International Energy Association. Latest trends in $\mathrm{co} 2$ emissions (Global Energy and co2 status report). Paris, France(2018)

10. Corinme,L.Q., Anand, M.,Oliver, B.,Gail, W., Glen P.,\& Dabog: Emission are still rising: ramp up the cuts. Nature International Journal of Science. vol.564. Springer Nature (2018) 27-30.

11. Roberts, J. T.,\& Grimes, P. E.:Carbon intensity \& Economic development 1962-91: A Brief exploration of the environmental Kuznets Curve. World Development, vol,25. 2. Elsevier Science ltd. (1997) 191-198.

12. Kunnas, J., Myllyntaus,T.: The Environmental Kuznets Curve Hypothesis and Air pollution in Finland.

13. Scandinavian Economic History Review. Vol 55. 2. Taylor and Francis, UK (2007) 101-127

14. Nain, Ahmad and Kamaiah: Economic growth, Energy consumption and CO2 emissions in India (2017). International Journal of Sustainable Energy, Vol. 36:8, p. 807-824.

15. Bhat and Mishra: Indian growth and Development Review, Kyoto protocol and CO2 emission vol. 11 Issue 2, pp. 152-168

16. $\mathrm{Xu}$ Guangyue \& Song Deyong: An Empirical Study on the Environmental Kuznets Curve for China's Carbon Emissions Based on Provincial Panel Data, Chinese Journal of Population and Environment. 9:3, 66-76.

\section{AUTHORS PROFILE}

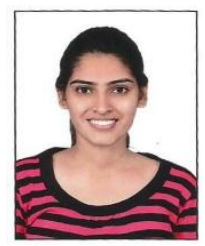

Sunita Choudhary, PhD scholar at Department of Economics at Manipal University Jaipur, her research area is Energy Economics. She cleared her NET in Economics in January 2018. She completed her master's and bachelor's from Department of Economics, University of Rajasthan and from St. Xavier's College, Jaipur respectively. She did her Schooling from St. Xavier's Sen. Sec. School Jaipur.

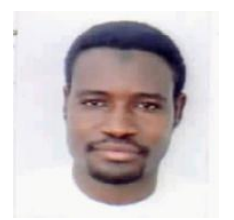

Mohammed Sani Ibrahim scholar at Department of Economics at Manipal University Jaipur, his research area is Energy Economics. He completed his master's and bachelor's from Department of Economics, NIMS University.

Dr Oum Kumari R, Assistant Professor has done her graduation and Post-Graduation from University of Madras. She also is a university Rank Holder in BA

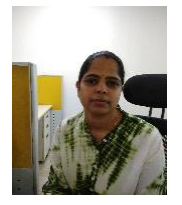
Economics Hons. She pursued her M. Phil from Presidency College and $\mathrm{PhD}$ from Malaviya National Institute of Technology. Research in the Areas of Energy Management and Renewables has been taken up in last ten years. Twelve articles in reputed journals has been published and Book Chapters in the area of Finance is also to her credit. 